\title{
Catalytic performances of Cu-Mn-Ce oxide/SiC monolithic catalyst for oxidation of toluene under microwave irradiation
}

\author{
Bin Guo, Xurui Hu*, Xin Wang, Shuo Zhang \\ School of Environmental Science and Engineering, Hebei University of Science and Technology, S \\ hijiazhuang 050018, China \\ *email:huxurui5200@163.com
}

Keywords: Catalytic combustion; Silicon carbide (SiC); Microwave irradiation; Monolithic catalyst

\begin{abstract}
A monolithic Cu-Mn-Ce oxides supported on a ring of silicon carbide (SiC) with molar ratios 1:2:1 were prepared by the sol-gel combustion method without any binder. The catalysts were characterized by scanning electron microscopy (SEM), X-ray diffraction (XRD), and Brunauer-Emmett-Teller method (BET). Toluene was chosen as a model compound to evaluate the catalytic activity in a conventional fix-bed quartz reactor. The results showed that the mixed oxides adhered firmly to the ring of silicon carbide surface. Compared with the conventional heating, the $\mathrm{Cu}-\mathrm{Mn}$-Ce oxides monolithic catalysts under microwave irradiation showed higher activity for the combustion of toluene in the low temperature range $\left(350{ }^{\circ} \mathrm{C}<400{ }^{\circ} \mathrm{C}\right)$ and the $90 \%$ of toluene conversion was achieved at $350{ }^{\circ} \mathrm{C}$.
\end{abstract}

\section{Introduction}

Toxic volatile organic compounds (VOCs) become the focus and hot spots of scientific research. Because it can cause a lot of disease such as headache, nausea, intoxication and even cancer after long exposures. What's more, it can also destruction of the ozone layer indirectly and produce photochemical smog [1]-[3].VOCs waste gas mainly comes from petroleum chemical industry, pharmaceutical, paint, motor vehicle, footwear and other industries. How to effectively control VOCs pollution has become an important task of the prevention and control of atmospheric pollution. Then many techniques have been studied and applied to treat waste VOCs, such as adsorption [4], biological process [5], and combustion method [6] etc.. Catalytic combustion has the advantages of low light-off temperature, wide application range, high efficiency and no secondary pollution. Transition metals oxides, such as copper oxide and manganese oxide, as catalytic active component increases catalytic capacity by generating more surface oxygen species and creating more active sites on catalyst [7]-[9]. However, conventional heating method may cause catalyst sintering. Therefore, there is a need for a new heating method in catalytic oxidation of VOCs to overcome this weakness.

Microwave is a type of electromagnetic wave with high thermal effect has been widely used in the treatment of solid waste [10], waste water [11] and waste gas [12] because of its low thermal inertia and dipole polarization. This helps to avoid catalyst sintering. However, microwave irradiation is selective. It only heats the materials that absorb microwave energy. It's reported that silicon carbide (SiC) [13] is excellent in absorbing microwave energy. There are few reports on the process of VOCs waste gas by a microwave irradiation method.

In this study, we focus on the advantages of microwave heating over conventional heating on $\mathrm{Cu}-\mathrm{Mn}$-Ce oxides/SiC monolithic catalyst prepared by the sol-gel method without any binder during catalytic combustion of toluene. Various characterizations including BET, SEM and XRD are applied to investigate the surface properties of the monolithic catalyst.

\section{Experimental}

\section{Catalysts preparation}

The ring of silicon carbide is $\varphi 3.5 \mathrm{~mm} \times 7 \mathrm{~mm}$ and $6 \mathrm{~mm}$ length. Copper nitrate, manganese nitrate, 
and cerium nitrate were mixed in molar ratios of 1:2:1 in an appropriate volume of distilled water to obtain a transparent solution. The same moles of citric acid were added into the nitrate solution and ammonia water were added into the mixed solution to adjust $\mathrm{pH}$ to 6 . The solution was heated to $70{ }^{\circ} \mathrm{C}$ and stirred until it became viscous. Then the rings of silicon carbide were immersed in this viscous solution for $20 \mathrm{~min}$. It was then dried at $120{ }^{\circ} \mathrm{C}$ for $12 \mathrm{~h}$ and then calcined at $550{ }^{\circ} \mathrm{C}$ for $4 \mathrm{~h}$. The coating procedure was repeated to achieve the desired loading.

\section{Activity test}

A quartz glass tube $(\mathrm{r} \times \mathrm{L}=40 \mathrm{~mm} \times 1100 \mathrm{~mm})$ was manufactured to test the activity of the catalyst. $\square$ Then the catalysts were packed in the tube about $100 \mathrm{~mm}$ high as shown in the Fig.1. Gaseous VOCs were generated by flowing air coming from an air pump controlled by flowmeter through liquid toluene in a glass bottle. The toluene-containing stream was mixed with the air stream introduced through another flowmeter. In the microwave-heating reactor, toluene gas entered the bed from the top of the reactor and was oxidized on the surface of the catalyst. And in the conventional heating reactor, toluene gas entered the bed from the right to the left. Inflow and outflow gas were analyzed by gas chromatography to determine the removal efficiency. The whole experimental process was shown in Fig. 2.

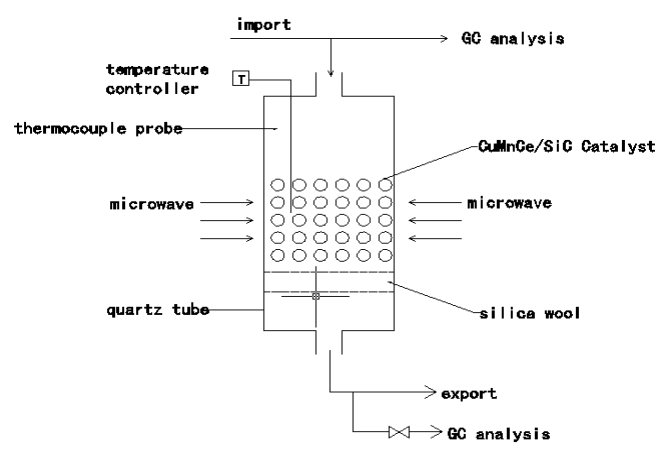

Fig.1 Diagram of microwave reactor

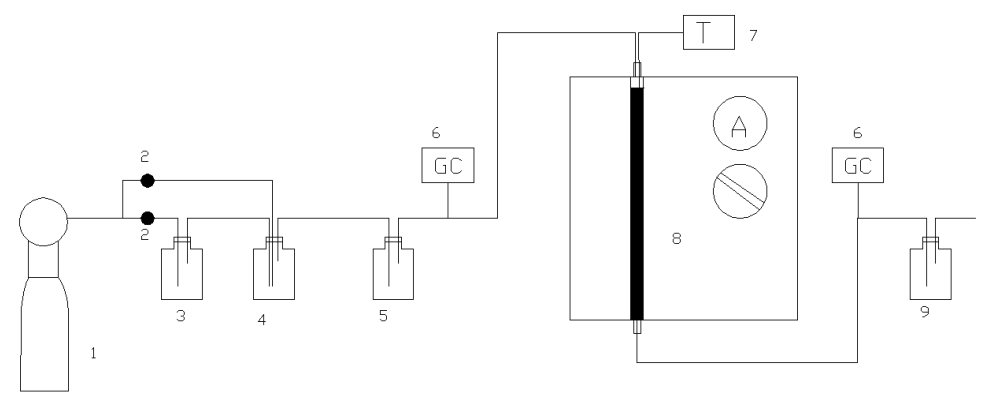

Fig.2 Schematic diagram of experimental process (1.cylinder; 2.flowmeter; 3.toluene volatilizer; 4.mixture; 5.buffer; 6.gas chromatograph; 7.temperature controller; 8.microwave reactor; 9. absorption bottle)

\section{Catalyst characterization}

The surface area $\left(\mathrm{S}_{\mathrm{BET}}\right)$ was determined by BET method from $\mathrm{N}_{2}$ adsorption isothermal at $-196{ }^{\circ} \mathrm{C}$ (NOVA 2000e). X-ray diffraction (XRD) patterns were collected on an ARL SCINTAG $\mathrm{X}$ 'TRA powder diffractometer using $\mathrm{Cu} \mathrm{Ka}$ radiation. The working voltage of the instrument was $45 \mathrm{kV}$ and the current was $40 \mathrm{~mA}$. The intensity data were collected at room temperature in a $2 \theta$ range from $20^{\circ}$ to $100^{\circ}$. The morphology was carried out using SEM (S4800). Samples were need to spray gold processing before the test.

Ultrasonic test was performed to evaluate the cohesive content of the active phase. The samples were subjected to ultrasonic cleaning by being immersed in water inside a glass vessel and in an 
ultrasonic vibration cleaner at $40 \mathrm{kHz}$ for 20 min. After ultrasonic cleaning, the samples were dried at $120^{\circ} \mathrm{C}$ for $4 \mathrm{~h}$ and weighed to compare with the samples before coating.

\section{Results and discussion}

\section{Catalyst characterization}

The morphology of the bare substrate (the ring of $\mathrm{SiC}$ ) and $\mathrm{Cu}-\mathrm{Mn}-\mathrm{Ce}$ oxides/SiC catalyst is shown in Fig. 3. The surface of ring (Fig. 3 (a)) is irregular with various pore structures; this feature benefits the adhesion between the active phase and the substrate. Fig. 3 (b) shows the morphology of the $\mathrm{Cu}-\mathrm{Mn}$-Ce oxides/SiC catalysts. The comparison between the surface of the bare SiC (Fig. 3(a)) and that of Cu-Mn-Ce oxides/SiC (Fig. 3(b)) revealed the appearance of particles agglomerated in the latter. Also evident, the macroporosity of the support disappeared as consequence of the coating. This result suggested the uniform distribution of the catalyst over the SiC. Fig.3 (c) and (d) show the photos of the ring of SiC before and after coating. Ultrasonic test was employed to test content of the active phase. In order to evaluate the efficiency of the dip-coating procedure, it was carried out in consecutive steps to measure the amount of washcoating loading deposited at each step for different pieces of monoliths. The results are shown in Fig. 4. The loading obtained was increased as the number of coating increased. The oxide catalysts loading increased to $1.2 \%$ after the third coating. The BET surface areas of the powder catalyst is $17.4 \mathrm{~m}^{2} / \mathrm{g}$ and the $\mathrm{Cu}-\mathrm{Mn}-\mathrm{Ce}$ oxides/SiC is too little to detect in the instrument.
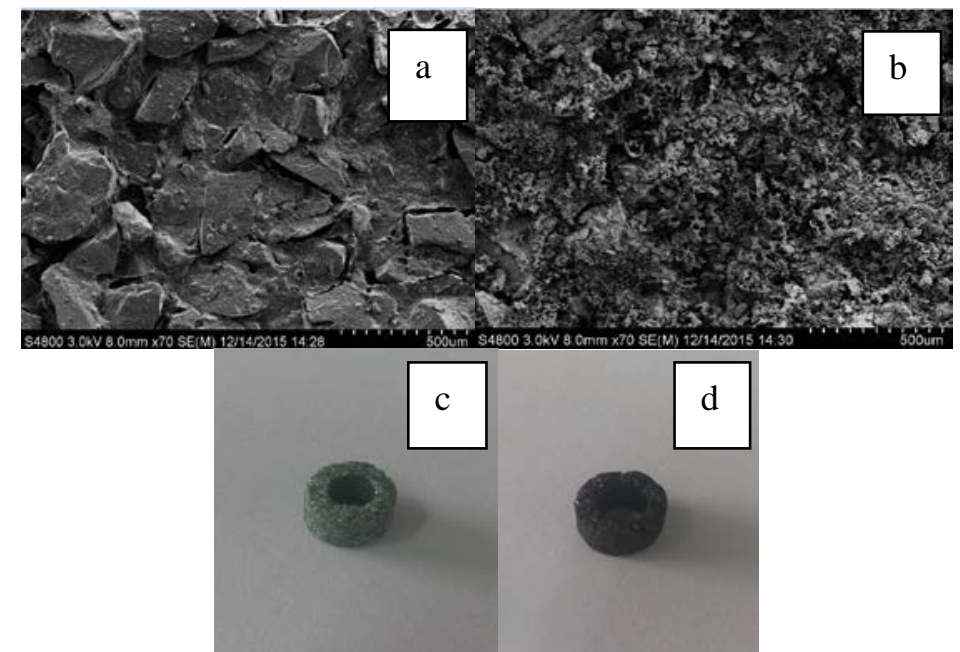

Fig.3. SEM images of the ring of SiC (a) and Cu-Mn-Ce oxides/SiC catalysts (b). The images of the ring of $\mathrm{SiC}$ (c) and one $\mathrm{Cu}-\mathrm{Mn}-\mathrm{Ce}$ oxides/SiC catalyst(d).

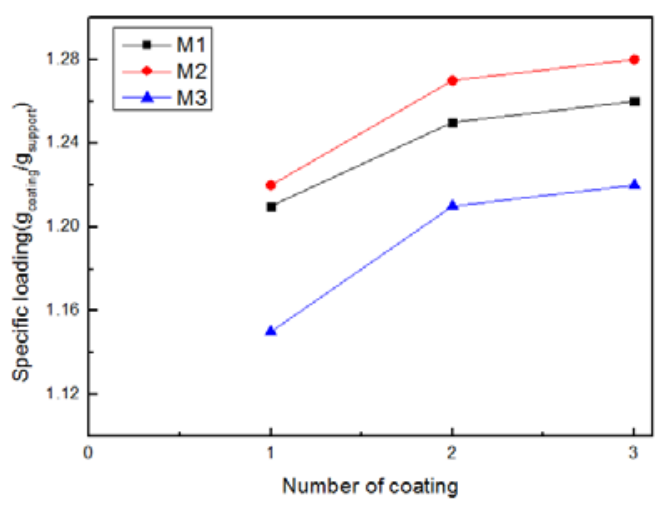

Fig.4 Cumulative specific load vs number of coating steps obtained on different batch of SiC

(M1, M2, M3) coated with Cu-Mn-Ce oxides sol.

Fig. 5 presents the XRD spectra of $\mathrm{Cu}-\mathrm{Mn}$-Ce oxides/SiC catalysts and $\mathrm{Cu}-\mathrm{Mn}$-Ce oxide catalysts prepared on the ring of $\mathrm{SiC}$. Because of the strong presence of the diffraction lines of $\mathrm{SiC}$ and it is overlapped with some of the reflections of the oxide phases of the catalysts, there are few observable XRD peaks due to $\mathrm{Cu}-\mathrm{Mn}$-Ce oxide phases. The diffraction peaks of the $\mathrm{Cu}-\mathrm{Mn}$-Ce 
oxides were detected corresponding mainly to $\mathrm{CeO}_{2}$ phase and a few peaks was assigned to $\mathrm{MnO}$ and $\mathrm{CuO}$ phase, which most probably due to incorporation of the copper and manganese ions into the $\mathrm{CeO}_{2}$ lattice.

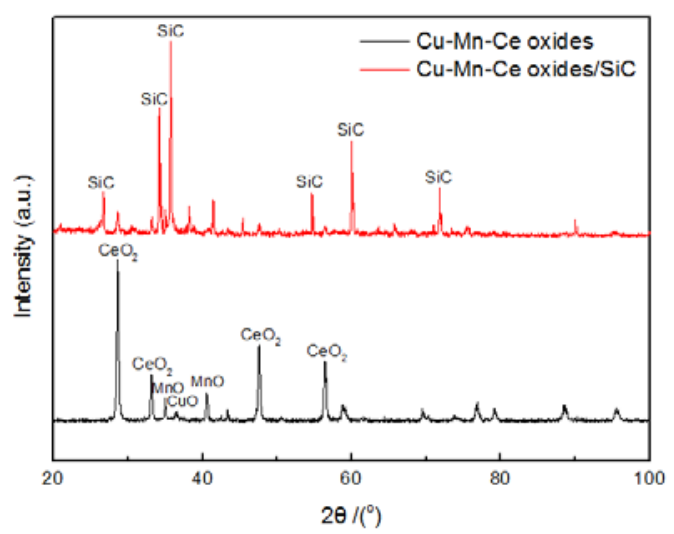

Fig. 5 XRD patterns of Cu-Mn-Ce oxides/SiC catalysts and Cu-Mn-Ce oxides catalysts

\section{Catalytic combustion of toluene on $\mathrm{Cu}-\mathrm{Mn}$-Ce oxides/SiC catalysts under microwave heating and conventional heating}

The catalytic activity of $\mathrm{Cu}-\mathrm{Mn}-\mathrm{Ce}$ oxides/SiC catalysts for the catalytic combustion of toluene is shown in Fig. 6. As shown in Fig. 6. compared to the conventional heating, the monolithic catalyst under microwave heating shows much higher activity in low temperature range. 90\% of toluene conversation can be achieved at $350{ }^{\circ} \mathrm{C}$ under microwave heating, while only $40 \%$ of that can be obtained at the same temperature under conventional heating. This result shows microwave heating is a very excellent potential to process removal of VOCs.

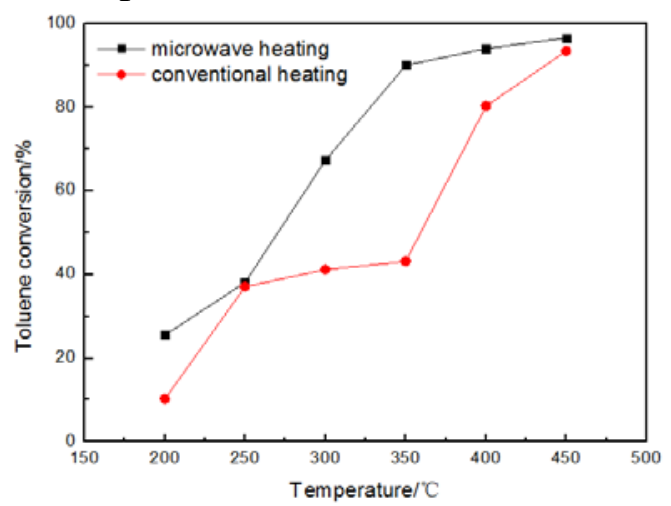

Fig.6. Comparison of toluene oxidation activity of $\mathrm{Cu}-\mathrm{Mn}$-Ce oxide/SiC monolithic catalyst under microwave heating and conventional heating.

\section{Conclusion}

In this study, a novel Cu-Mn-Ce oxide/SiC monolithic catalyst was prepared by sol-gel method, characterized and tested for catalytic toluene oxidation. Based on XRD results of Cu-Mn-Ce oxide catalyst, $\mathrm{CeO}_{2}$ phase was the main phase in the mix-oxides, which mainly related to incorporation of the copper and manganese ions into the $\mathrm{CeO}_{2}$ lattice. Compared with conventional heating, monolithic catalyst showed much better catalytic activity for toluene oxidation under microwave heating in the low temperature range. At $350{ }^{\circ} \mathrm{C}, 90 \%$ of toluene conversion was obtained under microwave heating, while only $40 \%$ under conventional heating. 


\section{Acknowledgement}

This work were financially supported by the National Science-technology Support Plan Project of China (Project No.2014BAC23B04-03) and Foundation of Hebei Province (Project No.14273712D)

\section{References}

[1]Parmar G R, Rao N N. Emerging control technologies for volatile organic compounds. Critical Reviews in Environmental Science and Technology, 2009, 39(1): 41.

[2]Mitsui T, Tsutsui K, Matsui T, Kikuchi R, Eguchi K. Support effect on complete oxidation of volatile organic compounds over Ru catalysts [J]. Applied Catalysis B: Environmental, 2008, 81: 56-63.

[3]Azalim S, Brahmi R, Agunaou M, Beaurain A, Giraudon J-M, Lamonier J-F. Washcoating of cordierite honeycomb with Ce-Zr-Mn mixed oxides for VOC catalytic oxidation [J]. Chemical Engineering Jounal, 2013, 223: 536-546.

[4]Parmele C, Kovalcson T. Adsorption: carbon. In: Rafson H J, ed. Odor and VOC Control Handbook. New York: McGaw-Hill, 1998.

[5]Bielefeldt A R, Stensel H D. Treating VOC-contaminated gases in activated sludge: mechanistic model to evaluate design and performance. Environmental Science \& Technology, 1999, 33(18): 3234-3240.

[6]Nedyalkova R, Ilieva L, Bernard M C, Hugot-Le Goff A, Andreeva D. Gold supported catalysts on titania and ceria, promoted by vanadia or molybdena for complete benzene oxidation. Materials Chemistry and Physics, 2009, 116(1): 214-218.

[7] Vu V H, Belkouch J, Ould-Dris A, Taouk B. Catalytic oxidation of volatile organic compounds on manganese and copper oxides supported on titania. AIChE Journal, 2008, 54(6): 1585.

[8]Tang $\mathrm{X} \mathrm{F}, \mathrm{Xu} \mathrm{Y} \mathrm{D,} \mathrm{Shen} \mathrm{W} \mathrm{J.} \mathrm{Promoting} \mathrm{effect} \mathrm{of} \mathrm{copper} \mathrm{on} \mathrm{the} \mathrm{catalytic} \mathrm{activity} \mathrm{of}$ $\mathrm{MnO}_{\mathrm{x}}-\mathrm{CeO}_{2}$ mixed oxide for complete oxidation of benzene. Chemical Engineering Journal, 2008, 144(2): 175-180.

[9] Ma R, Su X, Jin L, Lu J, Luo M. Preparation and characterizations of Ce-Cu-O monolithic catalysts for ethyl acetate catalytic combustion. Journal of Rare Earths, 2010, 28(3): 383.

[10]Haili Liu, Xiaoqian Ma, Longjun Li, et al. The catalytic pyrolysis of food waste by microwave heating. Bioresource Technology, 2014, 166: 45-50.

[11]Yuan Maobiao, Ma Xiongfeng, Wang Shuping, et al.Environmental protection of chemical industry [J], 2013, 33(6): 513-517.

[12]Yet-Pole I, Liu Y C, Han K Y, She T C. Construction of a lowpressure microwave plasma reactor and its application in the treatment of volatile organic compounds. Environmental Science \&Technology, 2004, 38(13): 3785-3791.

[13]Kim T H, Rupani H, Pallavkar S, Hopper J, Ho T. Destruction of toxic volatile organic compounds (VOCs) in a microwave-assisted catalyst bed. Journal of the Chinese Institute of Chemical Engineers, 2006, 37(5): 519-526. 